\title{
Screening for coeliac disease among Egyptian children
}

Soha M. Abd El Dayem¹, Azza Ahmed Aly², Esmat Abd El Gafar², Hesham Kamel³

1Department of Paediatrics, National Research Centre, Cairo, Egypt

2Department of Clinical and Chemical Pathology, National Research Centre, Cairo, Egypt

${ }^{3}$ Department of Paediatrics, Cairo University, Egypt

Submitted: 7 May 2008

Accepted: 28 October 2008

Arch Med Sci 2010; 6, 2: 226-235

DOI: 10.5114/aoms.2010.13900

Copyright (c) 2010 Termedia \& Banach

\section{Abstract}

Introduction: To screen for coeliac disease in Egyptian children with nonendocrinal short stature, refractory iron deficiency anaemia and type 1 diabetes. Also, to evaluate the sensitivity and specificity of different serological tests for diagnosis of coeliac disease (CD).

Material and methods: The study included 292 patients with clinical risk of CD. Testing for coeliac antibodies was performed, together with upper gastrointestinal endoscopy and small intestinal biopsy.

Results: Eleven patients (44\%) among 25 patients with refractory iron deficiency anaemia, 23 patients (34.3\%) among 67 patients with non-endocrinal short stature, and 6 patients (3\%) among 200 patients with type I diabetes mellitus were diagnosed by jejunal biopsy as having coeliac disease. AGA (IgG) had the highest sensitivity for diagnosing CD $(80.0 \%)$ followed by the TTG $(72.7 \%)$ antibody, while ARA had the highest specificity (95.9\%) followed by anti-EMA (94.7\%).

Conclusions: Coeliac disease is more common in Egyptian children with refractory iron deficiency anaemia, non-endocrinal short stature and type 1 diabetes than was previously thought; therefore it is mandatory to screen such patients for CD. Serological tests showed fairly good sensitivity and specificity for the diagnosis; however, intestinal biopsy remains the cornerstone for definitive diagnosis of patients with immunological reaction to gluten.

Key words: coeliac disease, short stature, insulin-dependent diabetes mellitus, refractory iron deficiency anaemia.

\section{Introduction}

Coeliac disease (CD) is an auto-immune inflammatory reaction characterized by partial or total atrophy of the proximal small intestinal villi, occurring after ingestion of gluten in genetically predisposed patients [1, 2].

Inflammatory denudation of the villous surface gives rise to malabsorption of foodstuffs, folate, fat-soluble vitamins and iron. In children with severe mucosal damage, absorption of vitamins, zinc and protein is also affected [3]. It is common in children and adolescents with a variety of disorders, including children with recurrent or persistent gastrointestinal symptoms, dermatitis herpetiformis, dental enamel defects, osteoporosis, short stature, delayed puberty, persistent iron deficiency anaemia, asymptomatic individuals with type 1 diabetes, Down syndrome, Turner syndrome, Williams syndrome, selective immunoglobulin (IgA) deficiency and first degree relatives of individuals with coeliac disease $[4,5]$.
Corresponding author: Soha M. Abd El Dayem National Research Centre 1 Mathaf El Manial Street Ilhamy Hussein Building Flat 52

Cairo, Egypt

Phone: 0106716852

E-mail: S_eldayem@yahoo.com 
Many children and adults with coeliac disease have non-classical forms of the illness. So-called silent coeliac disease refers to partial or complete villous atrophy in seropositive patients who have no gastrointestinal or extra-intestinal complications. Subclinical coeliac disease refers to villous atrophy in seropositive patients who have extra-intestinal complications but few or no gastrointestinal complaints [6].

Troncone et al. [7] reported a strong association between HLA class II genes (Dq molecule) and the pathogenesis of $C D$. Recent studies have shown that in the intestinal mucosa of coeliac patients, there are T-cells that recognize gliadin peptides when presented by the $\mathrm{Dq}$ heterodimer $\left(\mathrm{A} 1^{*} 0501\right.$, $B 1^{*}$ 0201) [8, 9]. Children with autoimmune disorders such as type 1 diabetes, autoimmune thyroid disease and Sjogren's syndrome have a higher incidence of coeliac disease [10].

The frequency of cases of CD with atypical manifestations, especially in older children and adults, the existence of latent forms of the disease, and the presence of groups of patients considered at high risk for developing CD, together with the need to monitor relapses and compliance to diet in diagnosed cases, have prompted the search for non-invasive serological screening methods [11]. The use of serology resulted in an increased detection rate, although a true increase in incidence may have also occurred [12].

Although intestinal biopsy is the gold standard for final diagnosis of $C D$ and it is the only proof of a positive or negative response to a gluten-free diet [13], three main categories of circulating antibodies have been identified with potential value in the diagnosis and screening of CD: anti-gliadin (AGA), anti-reticulin (ARA) and anti-endomysial antibodies (EMA). Anti-endomysial antibodies have largely replaced anti-reticulin antibodies because of their greater sensitivity [14].

Tissue transglutaminase (tTG) has been identified as the main, if not sole, autoantigen recognized by endomysial antibodies in patients with CD. This enzyme, which is widely distributed in human organs, belongs to a family of calciumdependent enzymes. IgA class tTG autoantibodies may be a useful tool in diagnosis and follow-up of CD [7].

Scientific studies confirm that the average consumption of wheat of an Egyptian citizen is $150 \mathrm{~kg}$ per year. It is available mainly in bread, macaroni and other packed cake. There are difficulties in sticking to a gluten-free diet (GFD) in Egypt, it being less commercially available and more expensive [15].

Our aim is to screen coeliac disease in Egyptian children with non-endocrinal short stature, refractory iron deficiency anaemia and type 1 diabetes; and also to evaluate the sensitivity and specificity of different serological tests for diagnosis of CD.

\section{Material and methods}

It is a case control prospective study done after obtaining approval from the local institutional review board and human subjects protection. Written consent was obtained from patients and their parents.

This study included 292 patients, selected from the outpatient clinic of the National Research Centre and Cairo University Children's Hospital from 2004 to 2007. They represented the following groups (the number in each group related to the willingness of patients to enter the study and the prevalence of each disease).

\section{Group I: patients with refractory iron deficiency anaemia (25 patients)}

The study included 25 patients $<18$ years of age with refractory iron deficiency anaemia (not responding to iron therapy for 3 months in a dose of $6 \mathrm{mg}$ elemental iron/ $\mathrm{kg} / \mathrm{day}$ ).

The diagnosis of iron deficiency anaemia was based on the presence of haemoglobin concentration below the cut-off value of $<11 \mathrm{~g} / \mathrm{dl}$ for children 5 months to 5 years of age, reduced $M C V<75 \mathrm{fl}$, increased RDW > 14.5 and one or more of the following: serum ferritin $<10 \mathrm{mg} / \mathrm{dl}$ (cut-off value of $12 \mathrm{mg} / \mathrm{dl}$ ), serum iron $<50 \mu \mathrm{g} / \mathrm{dl}$ and transferrin saturation \% (serum iron/TIBC $\times 100)<15 \%[16]$.

\section{Exclusion criteria}

- Prior erosive, ulcerative or malignant disease of the gastrointestinal tract.

- Previous gastrointestinal surgery.

- Overt gastrointestinal bleeding within the past 3 months.

- Inability to access the duodenum for biopsy.

- Patients with parasites causing chronic blood loss, i.e. Ancylostoma or bilharziasis.

- Presence of occult blood in stools.

\section{Group II: patients with non-endocrinal short} stature (67 patients)

\section{Inclusion criteria}

- Height greater than 2.5 SDS below the mean for age.

- Growth velocity less than expected for their age.

- Delayed bone age.

\section{Exclusion criteria}

- Familial short stature (according to mid-parental height). 
- Constitutional delay of growth and puberty.

- Dysmorphic syndromes.

- Disproportional short stature (bone dysplasias and rickets).

- Chronic systemic diseases.

- Patients with endocrinal causes of short stature (primary hypothyroidism and growth hormone deficiency disorders in response to stimulation by ITT and clonidine tests).

- Turner syndrome diagnosed by karyotype.

\section{Group III: patients with type I diabetes mellitus} (200 patients)

They were selected among diabetics with variable duration of disease and variable glycosylated haemoglobin levels (controlled and uncontrolled).

All the above groups were subjected to full history taking (with special stress on the duration of disease and relation of symptoms to diet) and thorough clinical examination including anthropometric measurements (mainly weight and height, or length if needed). Height was determined with a Harpender stadiometer, weight was taken with standard underwear using a balance scale (Sica-company).

\section{Laboratory investigations}

For antibody detection $5 \mathrm{ml}$ of blood was obtained by venepuncture from each patient and sera were separated promptly, grossly haemolysed and lipaemic samples were excluded. The specimens were aliquoted and stored at $-20^{\circ} \mathrm{C}$ until the time of analysis.

Laboratory investigations were done in the form of IgA anti-endomysium for patients with refractory iron deficiency anaemia and diabetes mellitus, IgA anti-gliadin for patients with short stature, and IgG antibodies to tissue transglutaminase for patients with refractory iron deficiency anaemia, while IgG anti-gliadin and IgA anti-reticulin was done for all patients included in the study.

Anti-gliadin antibody (AGA) detection was performed by a solid phase enzyme immunoassay (ELISA), using kits from Immco Diagnostics for IgG AGA (Immco - USA/ Canada). Anti-reticulin antibody (ARA) detection was performed by indirect immunofluorescence using a commercial kit from Immco Diagnostics (Immco - USA/Canada). Antiendomysial antibody (EMA) detection was performed by indirect immunofluorescence (using monkey oesophagus as a substrate) using a commercial kit from Immco Diagnostics (Immco - USA/ Canada). Anti-tissue transglutaminase (TTG) IgG antibody detection was performed by an ELISA technique for the detection and semi-quantitation of anti-tissue transglutaminase IgG antibodies in human serum using a commercial kit from Immco Diagnostics (Immco - USA/Canada).

In addition, upper gastrointestinal endoscopy with small intestinal biopsies was done for only 98 out of the 292 studied patients. These included all patients with refractory iron deficiency anaemia and short stature and only type 1 diabetics with positive coeliac antibodies that justified the invasive upper gastrointestinal tract (GIT) endoscopy (only 6 out of the 200 studied patients).

At least two biopsies from the jejunum were obtained using conventional endoscopic forceps (open cup $8 \mathrm{~mm}$ ). Samples were carefully oriented on filter paper (Millipore) and fixed in 10\% formalin. Biopsies were embedded in paraffin wax, cut in sections $5 \mu \mathrm{m}$ thick, and stained with haematoxylin and eosin. Small bowel biopsies were evaluated by observers unaware of the clinical and endoscopic findings.

Coeliac disease was diagnosed with one or more positive serological tests and typical histological findings on jejunal biopsy: inflammatory enteropathy characterized by proliferation of intraepithelial lymphocytes, crypt hyperplasia and partial or complete atrophy of small intestinal villi [17]. Jejunal biopsy is considered the gold standard for diagnosis of coeliac disease.

Follow-up biopsy 6-11 months after starting a gluten-free diet was performed in 9 patients only (3 patients presenting with short stature and the remaining 6 with insulin-dependent diabetes mellitus [IDDM]), while the remaining patients refused.

As jejunal biopsy is considered the gold standard and from the ethical point of view we could not perform biopsy in normal healthy children, patients with no villous atrophy were considered to be the control group.

\section{Statistical analysis}

Data were summarized as percentages. Weight and height were transformed into SDS by the program Growth Vision version 2. Sensitivity, specificity, negative predictive value (NPV), positive predictive value (PPV) and diagnostic efficiency of all antibodies were calculated according to biopsy results[12].

\section{Sensitivity}

Sensitivity is defined analytically as the lowest amount of the analyte that can be detected. Epidemiologically, it is the measure of the ability to detect or identify $C D$.

$$
\begin{aligned}
& \text { Sensitivity }= \frac{\text { Number of true positives }}{\text { Number of true positives }+} \\
&+ \text { number of false negatives }
\end{aligned}
$$




\section{Specificity}

Specificity means, analytically, the degree of interference in the assay by extraneous substances that may be present in the sample, and epidemiologically, it is the ability of the test to identify the population without CD. Specificity (negative in health) is calculated as follows:

$\begin{aligned} \text { Sensitivity }= & \frac{\text { Number of true negatives }}{\text { Number of true negatives }+} \\ + & + \text { number of false positives }\end{aligned}$

\section{The predictive values}

The positive predictive value is the fraction of positive test results that are true positives. This is often rather low in CD markers, when the false positive rate of the test is high.

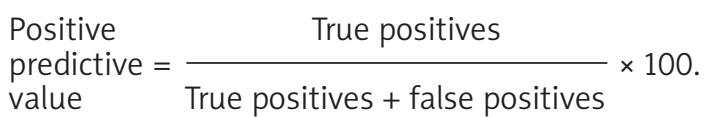

It is the probability that a person with a positive result actually has the disease. Similarly, the negative predictive value is the probability that a person with a negative result does not have the disease.

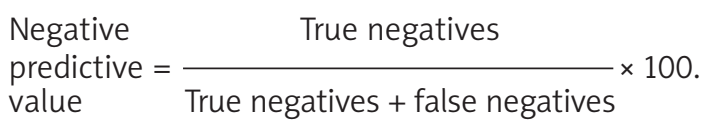

\section{Results}

This study included 292 patients with clinical risk of $C D$ divided into 3 groups: group I: refractory iron deficiency anaemia (25 patients), group II: non-

Table I. Symptoms and complications of coeliac disease in patients presenting with refractory iron deficiency anaemia

\begin{tabular}{|lcc|}
\hline Variables & \multicolumn{2}{c|}{ Coeliac } \\
\cline { 2 - 3 } & $N$ & $\%$ \\
\cline { 2 - 3 } & 5 & $11]$ \\
\hline Anorexia & 3 & 45.5 \\
\hline Heartburn & 3 & 27.3 \\
\hline Dyspepsia & 2 & 27.3 \\
\hline Vomiting & 2 & 18.2 \\
\hline Abdominal distension & 7 & 18.2 \\
\hline Abdominal pain & 5 & 63.6 \\
\hline Diarrhoea & 3 & 45.5 \\
\hline Underweight* & 5 & 27.3 \\
\hline Short Stature ${ }^{*}$ & 0 & 45.5 \\
\hline Haematemesis & 5 & 0 \\
\hline
\end{tabular}

*Underweight $=$ weight $\geq-2.5$ (SDS) below the mean

\#Short stature $=$ height $\geq-2.5$ (SDS) below the mean endocrinal short stature (67 patients) and group III: type 1 diabetes mellitus (200 patients).

Group I: the 25 patients with refractory iron deficiency anaemia included in the study (19 males and 6 females), with mean age $6.5 \pm 4.5$ year (1.0-17.0 year), mean age at presentation of anaemia $1.6 \pm 0.9$ year (1.0-4.0 year) and mean duration of anaemia $2.8 \pm 2.5$ year (0.2-10.0 year). The mean height SDS was $-1.8 \pm 2.2$ ( $-5.1-2.8$ SDS) and mean weight SDS was $-2.0 \pm 1.3$ (-3.9-1.4 SDS).

Eleven patients (44\%) were diagnosed by jejunal biopsy as having coeliac disease. Table I represents the symptoms and complications while Table II represents the endoscopic and histopathological findings of the 11 coeliac disease patients presenting with refractory iron deficiency anaemia.

Group II: the 67 short children included in this study (44 males and 23 females) had a male to female ratio of 1.9 , and a mean age of $7.9 \pm 3.9$ years (range 2-18 years), mean height of $-3.5 \pm 0.7$ SDS (range [-2.5]-[-5.0]), mean weight of $-2.7 \pm 1$ SDS and mean growth velocity $4.3 \pm 1.2 \mathrm{~cm} /$ year.

Twenty-three patients (34.3\%) were diagnosed by jejunal biopsy as having coeliac disease. Fifteen patients out of the 23 (65.2\%) had short stature as the only presentation. The rest had short stature in addition to other presentations (Table III).

- Cases no. 1, 3, 8 and 13 (17.4\%) had chronic diarrhoea with an age of onset less than 2 years.

- Case no. 3 had chronic diarrhoea and congenital myopathy.

- Case no. 9 had persistent hypocalcaemia and X-ray revealed osteoporosis.

- Case no. 5, 6 had anaemia and hepatomegaly and case no. 6 had atrial septal defect (ASD).

- Case no. 12 had failure to thrive.

Group III: it included 200 patients with IDDM (116 females and 84 males) with mean chronological age of 11.4 year. Prevalence of CD among the 200 IDDM cases was $3 \%$ ( 6 cases), 5 female patients and 1 male patient with male/female ratio of $1 / 5$. Table IV shows the clinical data while Table $V$ shows the

Table II. Study of endoscopic and histopathological findings of coeliac and non-coeliac disease patients presenting with refractory iron deficiency anaemia

\begin{tabular}{|lcccc|}
\hline \multirow{2}{*}{ Variables } & \multicolumn{2}{c}{ Coeliac } & \multicolumn{2}{c|}{ Non-coeliac } \\
\cline { 2 - 5 } & \multicolumn{2}{c|}{$[N=11]$} & \multicolumn{2}{c|}{$N=14$} \\
\cline { 2 - 5 } & $N$ & $\%$ & $N$ & $\%$ \\
\hline Oesophagitis & 3 & 27.3 & 8 & 57.1 \\
\hline Gastritis & 5 & 45.5 & 6 & 42.9 \\
\hline Duodenitis & 10 & 90.9 & 10 & 71.4 \\
\hline Jejunitis & 10 & 90.9 & 6 & 42.9 \\
\hline J. Inflammation\# & 6 & 54.5 & 12 & 85.7 \\
\hline
\end{tabular}

\# Jejunal inflammation was detected by histopathological examination of jejunal biopsies 
Table III. Demographic data and serological tests of patients with positive biopsy for coeliac disease presenting with short stature

\begin{tabular}{|c|c|c|c|c|c|c|c|c|}
\hline No. & $\begin{array}{l}\text { Age } \\
\text { [year] }\end{array}$ & Sex & $\begin{array}{l}\text { Presentation other than } \\
\text { short stature }\end{array}$ & AGA-IgG & AGA-IgA & ARA-IgA & Biopsy & Follow-up biopsy \\
\hline 1 & 12 & M & Ch. diarrhoea & 4 ve & +ve & +ve & Grade III (V.A.) & - \\
\hline 2 & 9 & $\mathrm{~F}$ & & $113.1^{*}$ & $129.5^{*}$ & +ve & Grade III (V.A.) & - \\
\hline 3 & 7.5 & $\mathrm{~F}$ & Ch. diarrhoea + myopathy & $253^{*}$ & $268^{*}$ & -ve & Grade III V.A. & $\begin{array}{l}\text { Grade II V.A. } \\
\text { myopathy } \\
\text { improved }\end{array}$ \\
\hline 4 & 10 & M & & 12.5 & 19.4 & -ve & Grade I V.A. & - \\
\hline 5 & 12 & M & Anaemia, hepatomegaly & $160.7^{\star}$ & 20 & $-v e$ & Grade II V.A. & - \\
\hline 6 & 6.7 & M & Anaemia, hepatomegaly + A.S.D. & $96^{*}$ & 15.5 & -ve & Grade II V.A. & - \\
\hline 7 & 6.9 & M & & 4.5 & 18.5 & -ve & Grade I V.A. & - \\
\hline 8 & 5 & M & Ch. diarrhoea & $205.9^{*}$ & 11.6 & -ve & Grade II V.A. & $\begin{array}{l}\text { The condition } \\
\text { improved after } \\
\text { gluten-free diet } \\
\text { before biopsy }\end{array}$ \\
\hline 9 & 14 & M & $\begin{array}{l}\text { Pain in L.L. and persistent } \\
\text { hypocalcaemia }\end{array}$ & +ve & -ve & +ve & Grade III V.A. & $\begin{array}{l}\text { N. Intestine } \\
\text { N. Ca level }\end{array}$ \\
\hline 10 & 7 & M & & $+v e$ & -ve & -ve & Grade I V.A. & N. Intestine \\
\hline 11 & 8 & M & & $151^{*}$ & -ve & $+v e$ & Grade III V.A. & \\
\hline 12 & 11.8 & $\mathrm{~F}$ & Failure to thrive* & $69^{*}$ & +ve & $+v e$ & Grade I V.A. & \\
\hline 13 & 6 & $\mathrm{~F}$ & Vomiting diarrhoea & $310^{*}$ & -ve & +ve & Grade III V.A. & \\
\hline 14 & 10.5 & $\mathrm{~F}$ & & $116^{*}$ & $136^{*}$ & $+v e$ & Grade III V.A. & \\
\hline 15 & 5 & $\mathrm{~F}$ & & $75^{*}$ & - & +ve & Grade III V.A. & \\
\hline 16 & 10.4 & M & & $87.2^{*}$ & $68^{*}$ & $+v e$ & Grade III V.A. & \\
\hline 17 & 6.1 & M & & $78.4^{*}$ & 26.5 & -ve & Grade II V.A. & \\
\hline 18 & 4.3 & $\mathrm{~F}$ & & 24.6 & 7 & +ve & Grade I V.A. & \\
\hline 19 & 3 & M & & $302^{*}$ & 17 & +ve & Grade III V.A. & \\
\hline 20 & 6 & M & & $321.4^{*}$ & 37.5 & $+v e$ & Grade III V.A. & \\
\hline 21 & 5 & $\mathrm{~F}$ & & 36 & 40 & -ve & Grade I V.A. & \\
\hline 22 & 4 & M & & $192^{*}$ & 47.5 & -ve & Grade II V.A. & \\
\hline 23 & 6 & $M$ & & $128^{*}$ & 45 & -ve & Grade II V.A. & \\
\hline
\end{tabular}

*Positive ASD: atrial septal defect, V.A. - villous atrophy AGA: anti-gliadin antibody, S.S. - short stature ARA: anti-reticulin antibody

laboratory data of the $6 \mathrm{CD}$ patients presenting with IDDM.

AGA (IgG) showed the highest sensitivity (80\%) followed by TTG (72.7\%). ARA (IgA) showed the highest specificity (95.6\%) followed by EMA (94.7\%) (Table VI).

\section{Discussion}

Coeliac disease or gluten sensitive enteropathy is a permanent intolerance of dietary gluten leading to mucosal damage in the proximal small bowel in genetically susceptible individuals, characterized by inflammation, crypt hyperplasia and villous atrophy which regress on withdrawal of gluten from the diet [17].

Ravikumara et al. [8] found the prevalence of CD in the Avon longitudinal study of parents and children to be at least $1 \%$, and more than $90 \%$ of cases of CD in children pass undiagnosed.

In our study, CD was diagnosed in 11 (44.0\%) out of the 25 refractory iron deficiency anaemia (IDA) studied patients.

The anaemia of $C D$ can be microcytic or macrocytic, and both iron and folic acid deficiencies have been described. Iron deficiency is commonly seen in $C D$ because of the frequent involvement of the proximal small intestine, where most iron 
Table IV. Clinical data of coeliac disease patients with insulin-dependant diabetes mellitus

\begin{tabular}{|c|c|c|c|c|c|c|c|}
\hline Case no. & Sex & $\begin{array}{l}C A \\
(Y)\end{array}$ & $\begin{array}{l}\text { Age of onset } \\
\text { IDDM (Y) }\end{array}$ & $\begin{array}{c}\text { Duration of } \\
\text { DM (Y) }\end{array}$ & GIT symptoms & Height SDS & Weight SDS \\
\hline । & $\mathrm{F}$ & & 10.0 & 1.0 & Repeated vomiting & & \\
\hline - before GFD & & 11 & & & & +0.25 & +0.5 \\
\hline - after GFD & & 11.75 & & & & +0.25 & +0.75 \\
\hline II & $\mathrm{F}$ & & 12.0 & 2.0 & Abdominal distension & & \\
\hline - before GFD & & 14.0 & & & & -0.25 & +0.75 \\
\hline - after GFD & & 14.75 & & & & -0.25 & +1.25 \\
\hline III & $\mathrm{F}$ & & 1.0 & 11.42 & Recurrent diarrhoea & & \\
\hline - before GFD & & 12.42 & & & & -1.75 & +0.5 \\
\hline - after GFD & & 13.33 & & & & -2.0 & +0.75 \\
\hline IV & $\mathrm{F}$ & & 3.0 & 6.0 & Recurrent diarrhoea & & \\
\hline - before GFD & & 9.0 & & & \& distension & -2.75 & -2.5 \\
\hline - after GFD & & 9.92 & & & & -3.0 & -2.0 \\
\hline V & $\mathrm{F}$ & & 5.0 & 8.5 & No GIT symptoms & & \\
\hline - before GFD & & 13.5 & & & & -2.25 & -1.75 \\
\hline - after GFD & & 14.42 & & & & -2.0 & -0.5 \\
\hline VI & M & & 4.0 & 12.25 & Persistent diarrhoea & & \\
\hline - before GFD & & 16.25 & & & & -3.5 & -3.5 \\
\hline - after GFD & & 17.0 & & & & -3.25 & -3.5 \\
\hline
\end{tabular}

${ }^{*} C A$ - chronological age, GIT - gastrointestinal tract, $F$-female, $M$ - male, GFD - gluten-free diet

Table V. Laboratory data of coeliac disease patients with insulin-dependant diabetes mellitus

\begin{tabular}{|c|c|c|c|c|c|c|}
\hline Case no. & $\mathrm{Hb}$ [g\%] & $\mathrm{HbA}_{1 \mathrm{c}}[\%]$ & AGA $[\mathrm{Eu} / \mathrm{ml}]$ & ARA & EMA & Biopsy \\
\hline I & & & & & & Grade III \\
\hline - before GFD & 12.0 & 10.5 & 6.0 & +ve & $+v e$ & V.A \\
\hline - after GFD & 12.3 & 10.0 & 4.5 & +ve & $+v e$ & \\
\hline II & & & & & & Grade II \\
\hline - before GFD & 11.5 & 11.1 & 6.2 & -ve & $+v e$ & V.A \\
\hline - after GFD & 11.8 & 11.7 & 5.8 & -ve & $+v e$ & \\
\hline III & & & & & & Grade II \\
\hline - before GFD & 11.6 & 12.0 & 11.6 & +ve & -ve & V.A \\
\hline - after GFD & 12.0 & 11.5 & 10.0 & +ve & -ve & \\
\hline IV & & & & & & Grade II \& III \\
\hline - before GFD & 11.5 & 10.5 & 30 & +ve & $+v e$ & V.A \\
\hline - after GFD & 12.0 & 11.2 & 28 & +ve & $+v e$ & \\
\hline V & & & & & & Grade II \\
\hline - before GFD & 12.0 & 10.7 & 8.6 & +ve & -ve & V.A \\
\hline - after GFD & 11.5 & 8.9 & 6.0 & $+v e$ & -ve & \\
\hline VI & & & & & & Grade II \\
\hline - before GFD & 6.5 & 8.7 & 34 & -ve & -ve & V.A \\
\hline - after GFD & 10.0 & 6.9 & 38 & $-v e$ & -ve & \\
\hline
\end{tabular}

V.A - villous atrophy, GFD - gluten-free diet, AGA - anti-gliadin antibody, ARA - anti-reticulin antibody, EMA - endomysium antibody 
Table VI. Sensitivity, specificity, PPV, NPV and accuracy of different antibodies of all studied patients. Total studied group (Total No. $=292)$

\begin{tabular}{|lccccc|}
\hline Antibody & Sensitivity [\%] & Specificity [\%] & PPV [\%] & NPV [\%] & Accuracy [\%] \\
\hline AGA (IgA) & 17.0 & 93.2 & 57.1 & 68.3 & 67.2 \\
\hline AGA (IgG) & 80.0 & 92.9 & 64.0 & 96.7 & 91.1 \\
\hline ARA (IgA) & 57.5 & 95.6 & 67.6 & 93.4 & 90.4 \\
\hline EMA (IgA) & 70.6 & 94.7 & 52.2 & 97.5 & 92.9 \\
\hline TTG (IgG) & 72.7 & 85.7 & 80.0 & 80.0 & 80.0 \\
\hline
\end{tabular}

PPV - positive predictive value, NPV - negative predictive value, AGA - anti-gliadin antibodies, ARA - anti-reticulin antibodies, AEM - anti-endomysium antibodies, TTG - anti-tissue transglutaminase

absorption occurs [19]. Because CD may result in intestinal malabsorption of iron, occult coeliac disease has been reported in 0 to $6 \%$ of adults presenting with iron deficiency anaemia (IDA) [20]. On the other hand, the reported incidence of IDA in $C D$ varies between 10 and $80 \%$, depending on the diagnostic criteria used [21]. Fisgin et al. [22], Masjedizadeh et al. [4], and Kalayci et al. [23] reported an incidence of 54.5, 3.2 and $66.7 \%$ respectively of IDA in a group of children with CD, which is much higher than in the general population.

In the current study, the most common reported symptoms in patients with CD presenting with refractory IDA were: gastrointestinal symptoms in the form of abdominal pain (63.6\%), diarrhoea and anorexia (45.5\% each), dyspepsia and heartburn (27.3\% each), vomiting and abdominal distension (18.2\% each). Complications detected in those patients were short stature (45.5\%), and underweight (27.3\%). Mody et al. [21] suggested that, although the association of IDA with CD is recognized, the setting is usually that of significant gastrointestinal symptoms and malabsorption and not a sole presenting sign.

Endoscopic and histopathological findings detected in patients with CD were duodenitis and jejunitis (90.9\% each), gastritis (45.5\%), oesophagitis (27.3\%), hiatus hernia (18.2\%) and jejunal inflammation detected by histopathological examination of jejunal biopsies (54.5\%).

Bhadad et al. [24] suggested that CD emerged as the single most common cause of short stature, followed by various endocrine disorders. Short stature by itself, even when GIT symptoms are totally absent, is an appropriate indication for jejunal biopsy.

Our study on group II patients (patients with non-endocrinal short stature) showed that 23 (34.3\%) out of 67 biopsied cases revealed total or subtotal villous atrophy diagnostic of CD. Our results are in agreement with De Lecea et al. [25], who reported an incidence of $C D$ in short children ranging from 25 to $33.8 \%$, while lower prevalence (12\%) was reported by Czerwionka-Szaflarska et al. [26]. This high prevalence of CD in our study may be related to the selection of a high risk group of short children after exclusion of endocrinal causes of short stature.

In the current study, follow-up intestinal biopsy was done for only 3 patients with non-endocrinal short stature who received a gluten-free diet (GFD) for 6 months following the first biopsy. Case no. 10, who presented with only short stature, showed normal intestinal biopsy findings. Case no. 9, who presented with pain in the lower limbs and limping in addition to short stature, persistent hypocalcaemia with increased levels of parathyroid hormone and alkaline phosphatase, and an X-ray revealing osteoporosis, improved following a glutenfree diet, the hypocalcaemia improved and jejunal biopsy revealed normal villi with no flattening. This is in agreement with Stazi et al. [27], who reported that osteoporosis is an atypical presentation of CD. Case no. 3, who presented with chronic diarrhoea and congenital myopathy, showed slight improvement of jejunal biopsy, i.e. villous atrophy changed from grade III to grade II, AGA-IgG remained positive but both diarrhoea and myopathy were improved. This is probably related to poor compliance of the patient. Also, this is in agreement with Cakir et al. [28], who reported that the rate of neurological problems is increased in children with CD. Neurological abnormalities should be carefully investigated early after the diagnosis of CD is made.

Coeliac disease is a life-long inflammatory autoimmune condition of the gastrointestinal tract affecting genetically susceptible individuals. The coexistence of CD and other autoimmune disorders, particularly IDDM, thyroid disease and dermatitis herpetiformis, has been reported by several authors $[17,29,30]$.

Screening of IDDM patients in our study for CD revealed that $6 / 200$ (3\%) (5 females and 1 male) had $C D$ as confirmed by jejunal biopsy. The most frequently encountered clinical presentation of the CD cases in this study was GIT manifestations (5/6, $83.3 \%$ ) in the form of repeated vomiting, abdominal distention and recurrent diarrhoea followed by anaemia with short stature $(2 / 6,33.3 \%)$ and repeated urinary tract infection $(1 / 6,16.6 \%)$. This agrees with Magazzu et al. [31], who reported that among 250 IDDM studied patients, 8/250 (3.2\%) 
have CD, 7/8 (87.5\%) presented with GIT manifestations and $1 / 8$ (12.5\%) presented with short stature. In contrast, Kaspers et al. [32] found that children with type 1 diabetes and CD were characterized by earlier onset of diabetes and decreased growth and weight gain.

The prevalence of CD in this study among 200 IDDM patients was nearly similar to that reported by Barera et al. [33] (3.2\%). However, it is lower than that reported by Salah et al. [34] (4\%), Goh and Banerjee [35] (4.4\%) and Novoa Medina et al. [36] (8\%). The prevalence of CD in our study among IDDM patients was based on the results of intestinal biopsy. But still this prevalence does not reflect the actual prevalence of $C D$ because a biopsy specimen was not taken for all IDDM patients.

Follow-up serological screening after 9-11 months of a gluten-free diet (GFD) in CD patients (group III) revealed that all serological markers are still positive. Two explanations for this finding are possible: first, poor compliance of patients to GFD is a possibility, as there are difficulties in sticking to a GFD in Egypt, it being less commercially available and more expensive. Secondly, serological screening follow-up was performed after 9-11 months on a GFD, which may not be sufficient for serological markers to disappear from the serum. Mäki et al. [37] reported that IgG AGA needs a long time, sometimes more than one year, to become negative. EMA was reported to persist for about 9 months, while ARA disappears in parallel with mucosal healing [38].

The standard diagnostic criteria of CD included the presence of the characteristic anti-gliadin or anti-tissue transglutaminase antibodies in serum, flattened mucosa on intestinal biopsy, and improved symptoms on a gluten-free diet [39].

In our study, serological screening tests for CD of all studied patients revealed that IgA EMA, IgG TTG, AGA (IgA), AGA (IgG) and ARA had sensitivity rates of $70.6,72.7,17.0,80.0,57.5 \%$, respectively; the specificity rates were $94.7,85.7,93.2,92.9$ and 95.6\%; positive predictive values were 52.2, 80.0, 57.1, 64.0 and $67.6 \%$; and negative predictive values were 97.5, 80.0, 68.3, 96.7 and 93.4\%, respectively.

Yachha el al. [40] found that IgA EMA, IgA TTG, AGA (IgA) and AGA(IgG) had sensitivity rates of 83 , 74,61 and 74\%, respectively; the specificity rates were $95,100,89$ and $26 \%$; positive predictive values were 95, 100, 88 and 55\%; and negative predictive values were $82,74,65$ and $45 \%$, respectively. They concluded that IgA TTG is useful for the diagnosis of $C D$, with sensitivity and specificity rates comparable to those of EMA, and this test is well suited for use in tropical countries such as India.

The present findings of lower sensitivity of AGA ( $\operatorname{lgA})$, EMA and ARA may be attributed to poor immune response of patients or IgA deficiency, which was not tested for in the present study group, age dependency of both IgG AGA and EMA, different cut-off values of the serological antibodies as regards $A G A$, or variation in the interpretation of immunofluorescence used for both ARA and EMA.

Hill and Holmes [41] reported that the diagnostic guidelines could be modified so that small bowel biopsy is no longer regarded as mandatory in patients with high tTG. This will avoid invasive procedures and may lead to more rapid diagnosis and earlier treatment for over half of new patients with CD. On the other hand, Rodrigues and Jenkins [13] reported that the diagnosis of $C D$ still requires upper gastrointestinal endoscopy and small bowel biopsy.

However, patients with other autoimmune diseases, such as autoimmune hepatitis and diabetes mellitus, can react positively with tTG by ELISA [42]. In addition, CD can occur in patients with IgA deficiency with an incidence 10-15-fold higher than the general population. In patients with IgA deficiency with CD, IgA antibodies to gliadin, endomysium, reticulin and tTG are usually negative. Such patients with IgA deficient CD are positive for IgG AGA. However, not all IgA deficient patients with CD are positive for IgG AGA. Thus, IgG EMA and IgG tTG are useful screening tests especially in patients with IgA deficiency [43].

A limitation of our study was the number of patients and written consent from parents of children for doing jejunal biopsy and cost of kits.

In conclusion, coeliac disease is more common in Egyptian children with refractory iron deficiency anaemia, non-endocrinal short stature and type 1 diabetes than was previously thought. Screening of high-risk groups, and of patients with such common symptoms, is becoming an accepted standard in practice.

Coeliac disease is frequently under-diagnosed because of its protean presentations. Serological tests showed fairly good sensitivity and specificity in our study. The advent of serological markers with high sensitivity and specificity is changing our understanding of the disease and its prevalence. However, intestinal biopsy remains the cornerstone for definitive diagnosis of $C D$ in patients with immunological reaction to gluten.

From this study, we suggest that the basis for diagnosis of $C D$ in children should be through early case-finding by a) knowledge about different presentations of the disease and factors affecting them, b) generous serological testing in patients with vague symptoms, and c) screening of risk groups.

Encouragement of diagnosed children and adolescents with CD to receive a gluten-free diet to prevent the occurrence of serious complications attributed to this disease is highly recommended. 


\section{References}

1. Marmouz F. Adult celiac disease. Allerg Immunol (Paris) 2007; 39: 23-5.

2. Kagnoff MF. Celiac disease: pathogenesis of a model immunogenetic disease. J Clin Investig 2007; 117: 41-9.

3. Jackson Allen PL. Guidelines for the diagnosis and treatment of celiac disease in children. Pediatr Nurs 2004; 30: 473-6.

4. Masjedizadeh R, Hajiani E, Hashemi J, Shayesteh AA Moula K, Rajabi T. Celiac disease in South-West of Iran. World J Gastroenterol 2006; 12: 4416-9.

5. Goel GK, Pokharna RK, Khatri PC, Senger GS, Joshi A, Khatri M, Dalal AS. Prevalence of celiac disease in first degree siblings of celiac disease patients. Indian J Gastroenterol 2007; 26: 46.

6. Freemark M, Levitsky LL. Screening for celiac disease in children with type 1 diabetes: two views of the controversy. Diabetes Care 2003; 26: 1932-9.

7. Troncone R, Maurano F, Rossi M, et al. IgA antibodies to tissue transglutaminase: an effective diagnostic test for celiac disease. J Pediatr 1999; 134: 166-71.

8. Ravikumara M, Nootigattu VK, Sandhu BK. Ninety percent of celiac disease is being missed. J Pediatr Gastroenterol Nutr 2007; 45: 497-9.

9. Bourgey MM, Calcagno GG, Tinto NN, et al. HLA-related genetic risk for celiac disease. Gut 2007; 56: 1054-9.

10. Yachha SK, Aggarwal R, Srinivas S, Srivastava A, Somani SK, Itha S. Antibody testing in Indian children with celiac disease. Indian J Gastroenterol 2006; 25: 132-5.

11. Mearin ML. Celiac disease among children and adolescents. Curr Probl Pediatr Adolesc Health Care 2007; 37: 86-105.

12. Green PH. The many faces of celiac disease: clinical presentation of celiac disease in the adult population. Gastroenterology 2005; 128 (4 Suppl 1): S74-8.

13. Rodrigues AF, Jenkins HR. Investigation and management of celiac disease. Arch Dis Child 2008; 93: 251-4.

14. Ozgenc F, Aksu G, Aydogdu S, et al. Association between anti-endomysial antibody and total intestinal villous atrophy in children with coeliac disease. J Postgrad Med 2003; 49: 21-4.

15. Abdul Salam Jumaa. Self sufficiency in wheat will not be achieved. J On Egyptian 2008; 1422.

16. World Health Organization, Food and Agriculture Organisation: International Conference on Nutrition: World Declaration and plan of action 1992. Food and Agriculture Organization of the United Nations. Rome Italy World Health Organisation, Geneva Switzerland, 1992.

17. Ch'ng $\mathrm{Cl}$, Jones MK, Kingham JG. Celiac disease and autoimmune thyroid disease. Clin Med Res 2007; 5: 184-92.

18. Hill ID, Driks MH, Liptak GS, et al. Guideline for the diagnosis and treatment of celiac disease in children: Recommendations of North American Society for Pediatric Gastroenterology, Hepatology and Nutrition. J Pediatr Gastoentrol Nutr 2005; 40: 1-19.

19. Singhal A, Moreea S, Reynolds PD, Bzeizi KI. Celiac disease and hereditary hemochromatosis: association and implications. Eur J Gastroenterol Hepatol 2004; 16: 235-7.

20. Karnam US, Felder LR, Raskin JB. Prevalence of occult celiac disease in patients with iron-deficiency anemia: a prospective study. South Med J 2004; 97: 30-4.

21. Mody RJ, Brown PI, Wechsler DS. Refractory iron deficiency anemia as the primary clinical manifestation of celiac disease. J Pediatr Hematol Oncol 2003; 25: 169-72.
22. Fisgin T, Yarali N, Duru F, et al. Hematologic manifestation of childhood celiac disease. Acta Haematol 2004; 111: 211-4.

23. Kalayci AG, Kanber Y, Birinci A, Yildiz L, Albayrak D. Prevalence of celiac disease as detected by screening in children with iron deficiency anaemia. Acta Paediatr 2005; 94: 678-81.

24. Bhadada S, Bhansali A, Kochhar R, et al. Does every short stature child need screening for celiac disease? J Gastroenterol Hepatol 2007; 100: 1440-6.

25. De Lecea A, Ribes-koninclx C, Polanco I, Ferrer-Calvete J. Serological screening (antigliadin and antiendomycium antibodies) for non-overt coeliac disease in children of short stature. Acta Paediatr Suppl 1996; 412: 54-5.

26. Czerwionka-Szaflarska M, Pawlowska M, Choreselski T, Swincow G, Sulej L. The value of IgA endomysium antibodies in diagnosis of coeliac disease among children. Paediatr Pol 1995; 70: 575-8.

27. Stazi AV, Trecca A, Trinti B. Osteoporosis in celiac disease and in endocrine and reproductive disorders. World J Gastroentrol 2008; 14: 498-505.

28. Cakir D, Tosun A, Polat M, et al. Subclinical neurological abnormalities in children with celiac disease receiving a gluten free diet. J Pediatr Gastroenterol Nutr 2007; 45: 366-9.

29. Buysschaert M. Coeliac disease in patients with type 1 diabetes mellitus and thyroid disorders. Acta Gastroenterol Belg 2003; 66: 237-40.

30. Shaoul R, Lerner A. Associated autoantibodies in celiac disease. Autoimmun Rev 2007; 6: 559-65.

31. Magazzu G, Bottaro G, Cataldo F, et al. Increasing incidence of childhood celiac disease in Sicily: results of multicenter study. Acta Pediatr 1994; 83: 1065-9.

32. Kaspers S, Kordonouri O, Schober E, Grabert M, Hauffa BP, Holl RW. German Working Group for Pediatric Diabetology. Anthropometry, metabolic control, and thyroid autoimmunity in type 1 diabetes with celiac disease: a multicenter survey. J Pediatr 2004; 145: 790-5.

33. Barera G, Bianchi C, Calisti L, Cerutti F, Dammacco F. Screening of diabetic children for coeliac disease with antigliadin antibodies and HLA typing. Arch Dis Child 1991; 66: 491-4.

34. Salah N, El Hamid Fa, Abdelghaffar S, El Sayem M. Prevalence and type of anaemia in young Egyptian patients with type 1 diabetes mellitus. East Mediterr Health J 2005; 11: 959-67.

35. Goh C, Banerjee K. Prevalence of celiac disease in children and adolescents with type I diabetes mellitus in clinic based population. Postgrad Med J Feb 2007; 83: 132-6.

36. Novoa Medina Y, Lopez-Capape M, Lara Orejas E, Alonso Blanco M, Camarero Salces C, Barrio Castellanos R. Impact diagnosis of celiac disease on metabolic control of type 1 diabetes. An Pediatr (Barc) 2008; 68: 13-7.

37. Mäki M, Hällström O, Huupponen T. Increased prevalence of coeliac disease in diabetes. Arch Dis Child 1984; 59: 739-42.

38. Khoshoo V, Bhan MK, Unsworth DJ, Kumar R, Walker Smith JA. Antireticulin antibodies: useful adjunct to histopathology in diagnosis of coeliac disease especially in a developing country. J Paediatr Gastroenterol Nutr 1988; 7: 864-6.

39. Lochman I, Martis P, Burlingame RW, Lochmanova A. Multiplex assays to diagnose celiac disease. Ann N Y Acad Sci 2007; 1109: 330-7.

40. Yachha SK, Aggarwal R, Srinivas S, Srivastava A, Somani SK, Itha S. Antibody testing in Indian children with celiac disease. Indian J Gastroenterol 2006; 25: 132-5. 
41. Hill PG, Holmes GK. Celiac disease: a biopsy is not always necessary for diagnosis. Aliment Pharmacol Ther 2008; 27: 572-7.

42. Clemente MG, Musu MP, Frau F, et al. Anti tissue transglutaminase antibodies outside celiac disease. J Pediatr Gastroenterol Nutr 2002; 34: 31-4.

43. Collin P, Maki M, Keyrilainen O, et al. Selective IgA deficiency and celiac disease. Scand J Gastroenterol 1992; 27: $367-71$ 